\title{
El concepto de piratería
}

CARL SCHMITT

TRADUCCIÓN Y PRESENTACIÓN DE YURI NOTTURNI UNIVERSIDAD DiEgo PORTALES | CHILE

CONTACTO: Y.NOTT@HOTMAIL.IT

\section{Presentación de la traducción}

A finales de 1937, el jurista y filósofo alemán Carl Schmitt publicó en las páginas de la revista Völkerbund und Völkerrecht un breve artículo de derecho internacional titulado Der Begriff der Piraterie [El concepto de piratería]. En esta concisa intervención, que presentamos aquí en español, la crítica, o mejor dicho, la polémica schmittiana en contra del uso del concepto de piratería por parte de los asistentes a la Conferencia de Nyon, adquiere en el curso de su densa exposición una perfecta consonancia teorética con aquellos breves escritos propios del derecho internacional que el Kronjurist del Reich - tal y como Waldemar Gurian lo bautizó en las páginas de Deutsche Briefe (Bendersky, 1983: 225) - había publicado en los últimos años en oposición al nuevo orden político y jurídico surgido después de la Primera Guerra Mundial. ${ }^{1}$

El interés de este pensador por el derecho internacional [Völkerrecht] no puede ser considerado el refugio apolítico de un intelectual que, empeñado en investigaciones de derecho constitucional, había sido progresivamente marginado y vigilado por el entourage del partido nacionalsocialista, como demuestra el dossier Rosenberg (Maschke, 1989: 29). Antes bien, este texto puede ser

\footnotetext{
1 Me refiero a los ensayos "Die Rheinlande als Objekt internationaler Politik" (1925), "Der Status quo und der Friede" (1925) y "Das Doppelgesicht des Genfer Völkerbundes" (1926). Según Schmitt, los acuerdos, por un lado, reflejaban la incapacidad de encontrar un principio jurídico capaz de legitimar un orden europeo en rápida transformación y, por otro, formaban parte de una perspectiva políticojurídica más amplia que, post-Versalles, a través de un universalismo "pacifista", tenía el fin de defender el status quo (Schmitt, 1988a: 40-41) y poner las bases para la outlawry of war y su transformación en un crimen internacional (Schmitt, 1994: 54-58).
} 
interpretado como uno de los síntomas de aquel vasto y complejo interés por las genealogías del derecho público en su totalidad. ${ }^{2}$ En efecto, Der Begriff der Piraterie, texto caracterizado por una perspectiva y un desarrollo de la discusión de carácter marcadamente jurídico - que bien ejemplifica la forma en que este pensador alemán se describía en su Glossarium como un jurista (Schmitt, 1991:17) - a través de la crítica a la desnaturalización del crimen pirateriae, deja percibir el parcial desarrollo de algunos temas de carácter particularmente importante para el derecho internacional que serán centrales en obras de la madurez como Land und Meer y, en particular, Der Nomos der Erde.

En este ensayo, Schmitt interpreta el intento de las naciones reunidas en Nyon por utilizar la categoría jurídica de piratería como una acción incongruente, algo que, pese a tener claramente un fin humanitario, resultaba profundamente cuestionable. Como el autor destaca puntualmente desde el íncipit del ensayo, la incoherencia del acuerdo se basaba en la interpretación de ciertos hundimientos de barcos mercantiles como "actos de piratería" (Schmitt, 1988d: 274). Esta decisión, que no era exenta al esprit du temps, se relacionaba con las acciones clandestinas desarrolladas por la marina italiana y alemana en apoyo a las fuerzas franquistas durante los primeros años de la Guerra Civil española, un momento histórico de grandes tensiones geopolíticas y sociales en que la comunidad internacional - presionada y cada vez más atemorizada por la opinión pública - intentaba evitar la agudización del conflicto, creando nuevos márgenes operativos para sancionar este tipo de violaciones sin dar lugar a una verdadera guerra. Claramente, la razón del acuerdo era, en primer lugar, salvaguardar la vida de la tripulación de los barcos mercantiles atacados en alta mar, teniendo en cuenta que aún estaba presente el recuerdo de la Primera Guerra Mundial y, en particular, del hundimiento del transatlántico británico Lusitania por parte de la Kriegsmarine [marina de guerra] en 1915. En segundo lugar, también se buscaba evitar la propagación de misiones clandestinas en apoyo a alguna de las dos partes beligerantes de la Guerra Civil Española, intentando evitar una posible propagación indiscriminada de este conflicto - aún nacional- a todo el Mediterráneo.

Por esta razón, las naciones firmantes, reunidas en esta ciudad suiza y lideradas por Francia y el Reino Unido, declaraban - haciendo referencia directa a la cuarta parte del anterior acuerdo de Londres de 1930- que las acciones

\footnotetext{
2 Sólo algunos años antes, en 1932, en una conferencia en Königsberg afirmaba: "El derecho internacional,
} precisamente como el derecho constitucional, es derecho político" (Schmitt, 1988b: 173). 
de los submarinos militares en contra de barcos y cruceros mercantiles tenían que ser consideradas como "acts contrary to the most and elementary dictate of humanity" [actos contrarios al mayor y más elemental mandato de la humanidad]. Dada la manifiesta violación del artículo 22 de este acuerdo, estas acciones podían ser reprimidas y sancionadas de manera unánime al ser consideradas "justly [...] as acts of piracy" [solamente como actos de pirateria].

Los submarinos protagonistas de dichas violaciones debían ser "counter-attacked and if possible destroyed" [contraatacados y, de ser posible, destruidos], una medida que, como los firmantes aclaraban en el párrafo 3 del acuerdo, podía ser utilizada legítimamente incluso en la circunstancia de que se hubiera encontrado simplemente "valid grounds for the belief that the submarine was guilty of the attack" [fundamentos válidos para creer que el submarino fuera culpable del ataque]. Esta medida ofrecía un margen operativo y legal muy amplio que, según el párrafo 4, podía ser utilizado por cualquiera de las potencias dedicadas a vigilar el respeto de dicha normativa. En este contexto histórico, si bien la Conferencia de Nyon no había introducido grandes modificaciones a la disciplina aplicable en la guerra submarina, limitándose a remitir al texto del acuerdo de Londres de 1930, intentaba introducir una configuración del crimen y un sistema de sanciones relacionado con una lógica que, a pesar de estas pequeñas modificaciones, se alejaba de la disciplina vigente mediante una forma de superfetación (Ruschi, 2009: 1226).

Según Schmitt, la voluntad de los signatarios era criminalizar estas acciones militares a través de una categoría jurídica aplicada en un contexto ajeno al original, es decir, sin considerar más a los submarinos y sus tripulaciones como barcos de guerra normales sujetos al derecho internacional vigente, sino considerándolos como enemigos universales libremente atacables por las marinas de todas las potencias interesadas en el área geográfica en que ocurrían las violaciones. Además, de acuerdo con la concepción continental del derecho internacional, los piratas eran sujetos que no tenían forma de relación orgánica con ninguna nación o aparato estatal. Eran actores desnacionalizados, outlaws, cuyas acciones eran actos estrictamente apolíticos que se desarrollaban en un topos desprovisto de soberanía. El lugar en que tomaba forma el animus furandi del pirata - el mar abierto - era considerado en la antigüedad como "un espacio jurídicamente vacío y privado de estatalidad" (Schmitt, 1988d: 275), una situación que, a causa de la evolución técnica y de los armamentos navales, ya era difícilmente aplicable a la contemporaneidad. En efecto, Schmitt afirma con razón que respecto a las acciones de estos piratas hodiernos 
"nadie podría sustentar que se muevan en un espacio privado de una estatalidad política" (Schmitt, 1988d: 275). Por ende, la intención de aplicar un crimen pirateriae resultaba contradictorio.

Esta deshumanización de la guerra submarina era un ejemplo discutible de cómo la comunidad internacional intentaba, por segunda vez, reformular los principios contenidos en el acuerdo de Washington de 1922, donde se consideraban dichas violaciones del derecho internacional como actos de piratería. Mientras que en el posterior acuerdo de Londres de 1930, en primer lugar, no se hacía referencia a este crimen pirateriae y, en segundo lugar, en el artículo 22 se equiparaban los submarinos a los barcos de guerra, despejando dudas sobre la disciplina aplicable.

La ausencia de una innovación conceptual resultaba paradójica para Schmitt. Se prefería utilizar un concepto añejo quitándole su contexto original con el fin de comparar un submarino militar con un barco pirata y su tripulación con una "banda romántica de merodeadores" (Schmitt, 1988d: 276). Esta decisión de negar la relación de los tripulantes de los submarinos con un Estado implicaba la imposibilidad de hacer recaer la responsabilidad de estas violaciones del jus in bello a un Estado determinado, según la praxis vigente. En su lugar, recaía en unos individuos, negando el carácter político de dichas acciones. ${ }^{3}$ Los submarinos y sus tripulaciones eran, así, puestos hors l'humanité como aquellos antiguos hostis humani generis que, debido a su general hostility, legitimaban una reacción o mejor: una "resistencia [en] común" (Schmitt,1988d: 274) por parte de toda la societas humani generis.

Como el autor enfatiza al respecto, el problema crucial del acuerdo es la transposición de un concepto tan romantizado con un contexto totalmente heterogéneo como el del derecho marítimo actual. Viejas fórmulas como la de "pirata" y "piratería" expresan magistralmente las numerosas aporías de un derecho que, frente a los nuevos resultados de la aplicación del desarrollo técnico a la guerra marítima, entra en contradicción intentando utilizar categorías inadecuadas y obsoletas para legitimar una nueva forma de reprimir al enemigo. Se trata, pues, de una criminalización del adversario que refleja el esfuerzo de la comunidad internacional por atenuar la tensión siempre más evidente y potencialmente destructiva entre Estados totales (totaler Staaten) ${ }^{4}$ a través de la identificación de "procedimientos colectivos" (Schmitt, 1988d:

\footnotetext{
3 Una politicidad que tampoco era negada a los partidos políticos revolucionarios, que exactamente por sus fines políticos no podían ser considerados piratas (Schmitt, 1988d: 275).

4 En relación con el concepto de "Estado Total" véase Schmitt (1988b, 1988c)
} 
277), momentos intermedios entre guerra y paz con el fin de aplazar cualquier tipo de guerra total (totaler Krieg) entre potencias (Schmitt, 1988c).

\title{
Referencias bibliográficas
}

Bendersky, Josef. (1983). Carl Schmitt: Theorist for the Reich. Princeton University Press.

Mascke, Gunther. (1989). "L'ufficio Rosenberg contro Carl Schmitt. Un documento del 1937". Behemot, V. 29-35.

Schmitt, Carl. (1988a). "Der Status quo und der Friede". En Carl Schmitt, Positionen und Begriffe im Kampf mit Weimar-Genf-Versailles, 1923-1939 (38-47). Duncker \& Humblot.

Schmitt, Carl. (1988b). "Die Wendung zum totalen Staat". En Carl Schmitt, Positionen und Begriffe im Kampf mit Weimar-Genf-Versailles, 1923-1939 (166-178). Duncker $\&$ Humblot.

Schmitt, Carl. (1988c). "Totaler Feind, totaler Krieg, totaler Staat". En Carl Schmitt, Positionen und Begriffe im Kampf mit Weimar-Genf-Versailles, 1923-1939 (268-273). Duncker \& Humblot.

Schmitt, Carl. (1988d). "Der Begriff der Piraterie". En Carl Schmitt, Positionen und Begriffe im Kampf mit Weimar-Genf-Versailles, 1923-1939 (274-277). Duncker E Humblot.

Schmitt, Carl. (1991). Glossarium. Aufzeichnungen der Jahre 1947-1951. Duncker \& Humblot.

Schmitt, Carl. (1994). Das internationalrechtliche Verbrechen des Angriffskrieges und der Grundsatz "Nullum crimen, nulla poena sine lege". Duncker \& Humblot.

Ruschi, Filippo. (2009). "Communis Hostis Omnium. La pirateria in Carl Schmitt". Quaderni Fiorentini per la Storia del Pensiero Giuridico Moderno, 38(2), 1215-1276.

\section{El concepto de piratería (1937)}

\author{
CARL SCHMITT
}

La Conferencia de Nyon, que tuvo lugar el 11 septiembre de 1937, es conocida como la conferencia anti-pirata o "sobre la piratería" (conference on piracy)

\footnotetext{
5 Título original: Der Begriff der Piraterie. Publicado en Völkerbund und Völkerrecht, 4, (1937), pp. 351354, y luego en Positionen und Begriffe im Kampf mit Weimar-Genf-Versailles, 1923-1939, Berlín, Duncker \& Humblot, 1988, pp. 240-243.
} 
cuyo texto oficial del acuerdo, firmado el 14 de septiembre por las nueve potencias participantes, declara que determinados hundimientos de barcos mercantiles a manos de submarinos, en violación a las reglas de la IV parte del acuerdo de Londres del 22 abril de 1930, tienen que ser considerados "actos de piratería". Según la fórmula antigua, a menudo repetida en esta conferencia, el pirata es definido como un "enemigo del género humano", hostis generis humani. Inicialmente, esto fue explicado a través de su "hostilidad general" (general hostility), ya que sus intenciones predatorias afectaban sin distinción a todos los Estados, razón por la cual, a su vez, cada Estado podía reprimir al pirata. Al respecto, el "enemigo en común" (solidarische Feind), como decía Karl Binding, tiene que "producir una resistencia en común" (Muss den solidarischen Widerstand erzeugen).

Según la precedente concepción del derecho internacional continental, era esencial para el concepto de piratería el hecho de que éste ocurriera en un espacio privado de cualquier estatalidad. Desde este punto de vista, fueron elaboradas una serie de antítesis conceptuales particularmente incisivas. No sólo era el hecho de que el escenario de la piratería fuese el mar abierto, en cuanto espacio sin Estado, y que no estuviera sujeto a ninguna soberanía territorial estatal. Como punto esencial vale también el hecho de que el reo era considerado, ya sea como premisa o consecuencia de su acción, desnacionalizado, es decir, apátrida y, en cualquier caso, [respecto al cumplimiento de dichas acciones] no autorizado ni retenido por ningún Estado. Además, la dirección de su actuar, de su ataque, no se dirigiría en contra de un Estado determinado, sino que eventualmente afectaría a una pluralidad de Estados, por lo tanto, se hablaría de animus furandi, etcétera. De acuerdo con la equiparación de lo estatal y lo político, la piratería era considerada una acción típicamente apolítica (unpolitische). La que hasta ahora ha sido la mejor introducción monográfica alemana sobre el tema es la de Paul Stiel (Der Tatbestand der Piraterie, 1904, p. 80) que concluye, en acuerdo con Hall, Rougier y Bishop, que: "La piratería no es una empresa que persigue fines políticos". Desde lo cual sigue la idea de que las acciones de los partidos revolucionarios - aunque fueran hechas en contra de potencias que no los reconocieron como partes beligerantes - no podrían ser consideradas como piratería "mientras en ellas sea reconocible el fin político de la iniciativa". La acción contra los piratas es, entonces, igualmente apolítica. No se trata de una guerra; de hecho, o se trata de una forma de justicia criminal según la legislación inglesa, o de una medida de policía marítima internacional, como destacan las construcciones [jurídicas] continentales. 
En toda esta doctrina sobre la piratería, tan rica en controversias, se mezclan elementos conceptuales antiguos, medievales y modernos, existiendo el peligro de que la realidad de la situación hodierna quede oculta bajo fórmulas engañosas y residuos conceptuales. Nosotros no hablamos de aquellos piratas antiguos o de la Edad Media. Frente a la efectiva organización del mundo contemporáneo en Estados, aquel carácter esencialmente no estatal y apolítico de la piratería se convierte repentinamente en algo problemático. Quien conoce la situación estatal y política del mediterráneo contemporáneo se encuentra, de pronto, frente a la pregunta sobre dónde este pirata apolítico tiene que encontrar el espacio jurídicamente vacío y privado de estatalidad en que pueda ejercer su oficio. Por suerte ya no existen "Estados corsarios" y "berberiscos"; han desaparecido con la conquista de Argel hace 100 años atrás. Los partidos revolucionarios, como se ha mencionado, a causa de su carácter político no pueden ser piratas. La técnica moderna de los medios de transporte y de las armas de guerras marítimas ha creado verdaderamente nuevas posibilidades para el ejercicio de la violencia en alta mar; sin embargo, al mismo tiempo, en lugar de formulaciones difícilmente reemplazables de tipo feudal-corporativo, también ha puesto las bases de organizaciones fuertemente centralizadas típicas de un Estado moderno que ha acrecentado enormemente sus posibilidades de control. Sólo se necesita confrontar los medios técnicos de poder de una policía moderna con aquellos del siglo XVIII y XIX para comprender a qué nos estamos refiriendo. Ya con estas medidas técnicas el Estado moderno se ha vuelto siempre más cerrado y, en este sentido, más total, mientras que el espacio vacío de la no estatalidad, necesario para el concepto de piratería, se vuelve siempre más marginal e insignificante. La contrapartida de esta totalidad del Estado es notoriamente una responsabilidad por todo lo que tiene lugar en su ámbito de poder personal o territorial. Pero ¿en qué medida cualquier individuo audaz o una banda de piratas podría llegar a conseguir un barco de guerra moderno y medios para su funcionamiento, evitando así cualquier contacto con un Estado? ¿Cómo limitarse a acciones "apolíticas" cuando no entra en cuestión una banda romántica de merodeadores, sino un interesante objeto de la acción internacional de las grandes potencias?

En los manuales y en los tratados sistemáticos, la figura del pirata a menudo se asoma junto con la cuestión del sujeto de derecho internacional. Aquí, el pirata juega un papel teoréticamente interesante, aunque modesto, ya que se niega que tenga el rango de sujeto de derecho internacional. Su acción no es un crimen de derecho internacional, desde el momento en que 
sólo los Estados, en cuanto sujetos del mismo, pueden cometer tales "crímenes de derecho internacional", mientras el pirata, precisamente por su carácter no estatal, no puede recaer bajo la esfera de poder ampliada a nivel internacional de un Estado. Esto es lo más destacable, dado que toda la humanidad desorganizada parece conformar un frente unitario contra él [pirata], al ser "enemigo del género humano". Pero, ya que el enemigo de la humanidad es sólo una entidad apolítica (unpolitische Größe) y que bajo un cierto aspecto se clasifica a través de lo que se reconoce como enemigo, entonces, una humanidad que no tiene ningún otro enemigo que este out-law apolítico es, por sí misma, una entidad apolítica.

Pero, al mismo tiempo, el problema de la piratería, definido en la conferencia antipirata, se ha convertido en un verdadero problema de derecho internacional, porque nadie podría sustentar que [el pirata] se mueva en un espacio privado de una estatalidad política. La reciente controversia acerca de las reglas internacionales aplicables a la guerra submarina, que apareció con el uso de esta arma, ha terminado en una significativa victoria de la concepción inglesa. Sin embargo, aún no se ha ratificado el acuerdo bélico de la conferencia de Washington del 6 febrero de 1922 (Strupp, Documents, p. 634). El artículo 1.2 parte del principio, hoy reconocido y fundamental, según el cual los submarinos en acción de guerra están sometidos a las reglas generales del derecho de guerra marítimo, en caso de secuestro de barcos mercantiles. Sin embargo, luego declara en el artículo 3 que cada persona al servicio de cualquier potencia que infringe estas reglas "whether or not such person is under orders of a governmental superior" es responsable "as if for an act of piracy". El artículo 4 se refiere, además, a la guerra de 1914-1918. La parte IV del acuerdo de Londres del 22 abril de 1930, por el contrario, no habla de piratería; sin embargo, plantea en su artículo 22 la obligación de los submarinos de cumplir con las reglas vigentes para los barcos de guerra, mencionando específicamente la obligación [frente a cualquier ataque] de dar advertencia preventiva y salvataje a los pasajeros, la tripulación y los cuadernos de bitácora. El Reich alemán se ha adherido a esta normativa del artículo 22, el 23 de noviembre de 1936, y la ha asumido como viculante desde aquel día. En el texto de la nota alemana de adhesión, el contenido literal se repite nuevamente. Que una violación de esta normativa se halla en contradicción con el derecho internacional, es claro. Sin embargo, aun si está clara la naturaleza de la piratería y la descripción de dichas violaciones del derecho internacional, sigue estando abierta la otra cuestión, a saber, el problema de la transposición de un concepto como el de piratería, tan lleno de consecuencias 
por dichas violaciones. No todas las violaciones a las reglas de la guerra naval son actos de piratería, que tienen como consecuencia que un Estado esté obligado a rendirse o a entregar o abandonar ciudadanos u órganos estatales de los que es responsable, empujándolos hacia aquel espacio libre y privado de estatalidad que ha sido, hasta ahora, el presupuesto jurídico de la piratería.

En cualquier caso, dado el desarrollo de la tecnología naval moderna descrita con anterioridad, ciertamente, surgen numerosos nuevos problemas acerca del derecho marítimo. Sin embargo, no pueden ser reconducidos a las viejas fórmulas, hoy romantizadas, que los presentaban como saqueadores del mar y tampoco pueden ser utilizados como una revitalización de la familiar controversia mundial de 1914-1918. Ellos, más bien, pertenecen a la amplia perspectiva que busca un nuevo y auténtico orden europeo e interestatal. Por un lado, se posicionan en relación con los esfuerzos de sustituir la guerra con procedimientos colectivos de diversos tipos (policía internacional, castigo de los vulneradores del derecho, proscripción y sanciones), creando sujetos capaces de actuar "en nombre de la humanidad". Por otro lado, se tiene que considerar el desarrollo del derecho internacional al que he dedicado mi atención en el número de junio de esta revista (Totaler Feind, totaler Krieg, totaler Staat), es decir, el hecho de que hoy, cuando se tiene que evitar el choque directo entre Estados totales en una guerra de carácter [igualmente] total, surgen una serie de conceptos y momentos intermedios entre guerra abierta y paz efectiva, dado que la mera posibilidad de una guerra total sugiere la formación de estas características intermedias. Si se tuviera que imponer la concepción inglesa de la piratería submarina como un concepto general de derecho internacional, entonces el concepto de piratería habría cambiado su puesto entrando en el sistema del derecho internacional. Se desplazaría desde el espacio vacío de una apolítica no-estatalidad hacia aquel espacio típico del derecho internacional de la posguerra, constituido por conceptos intermedios entre guerra y paz. 